\title{
Development Plans Replace Performance Reviews at Harvey Hotels
}

\section{Emphasis on personal development, individual abilities, and achieving goals creates sharper employees, better managers, and superior guest service}

\section{by John Beckert} and Kate Walsh

HOW CAN A young hotel company take the best traits of its original staff and propagate them throughout the organization as it expands? How can it recreate the sense of job ownership that motivated that first staff to provide the exceptional service that built the company's reputation-and its market share? And, how can new employees share the vision of the company's founders as expansion moves the home-office staff ever farther from the front lines?

Those were the questions we faced as Harvey Hotel Company of Dallas entered the 1990s. Like many others in the industry, Harvey's owners wanted to find new and better ways to develop employee skills so as to improve guest service, enhance job satisfaction, and reduce turnover. Before long, that challenge fell to those of us responsible for Harvey's training programs.

The underdog. The company started out very much as the underdog in a tough market. When founder Harvey $\mathrm{K}$. Huie decided to reject the conventional wisdom of picking up a franchise affiliation for his first hotel, company president Peter Kline knew that the new hotel company would have to

John Beckert is executive vice president of the Harvey Hotel Company. Kate Walsh, formerly that company's training manager, is now corporate director of training for Nikko Hotels International. 
achieve a high level of repeat

business to survive. The company

adopted a customer-centered service philosophy that challenged every Harvey employee to exceed guest expectations, not merely meet them.

"We knew that if our service was only as good as the competition's, we wouldn't succeed," recalled Kline. "We made an effort to hire individuals who genuinely cared about people, who would take some initiative and do a little more for our guests than just what was required. We created an environment that would nurture those characteristics. What resulted is a performance-based organization. Growth, advancement, compensation-all these things are predicated on performance."

From the start, employees were given personal responsibility for each guest's satisfaction. They were empowered to solve problems or handle special requests on the spot-to make executive decisions. By the same token, managers rolled up their sleeves and bussed tables or carried luggage in the name of better service. Guests were bowled over by the amount of personal attention they received. Within months, the hotel was enjoying occupancy levels far above the market average.

\section{A New Review}

The company thrived on the reputation for service created by that first Harvey Hotel's staff and management. But as the company grew-Harvey Hotels now owns seven properties and manages an eighth (under the names Harvey Hotels, Harvey Suites, and Bristol Suites)-its management observed that its performance-oriented philosophy was gradually becoming less focused. Despite a strong commitment to quality in hiring and a well-developed training program, there seemed to be a drift, a change in attitude from "Let's do it better" to "Let's simply get it done" seeping through the still-young organization.

Improving communication. Allowing Harvey's service standards to slip was not acceptable; therefore, since we were in charge of the company's training programs, we began to examine the methods by which the company's service standards were communicated. One area we targeted for investigation was the employees' performance-review process.

Harvey Hotels had followed the direction of most companies in conducting yearly reviews intended to provide continuity with initial training and ongoing feedback about an employee's strengths and weaknesses, and to reinforce the company's performance-based philosophy. More important, merit reviews were the primary method of identifying Harvey's high performers and rewarding them with increased responsibility and pay raises. The reviews effectively created the path for those individuals to grow with the company.

After studying the organization, we decided the company was not creating the best environment to develop and recognize outstanding performance, and that the review process itself was part of the problem. We found that the review was failing to communicate the company's performance expectations to each employee.

The partners and managers of the Harvey Hotel Company try to be direct and honest with the company's employees and expect the employees to be equally open. But our study found that the employees were reluctant to give feedback to their supervisors. As a result, the reviews tended to be one-sided. Managers had no idea of their employees' expectations, and missed opportunities to align employees' goals with the company's. Worse yet, employees weren't coming out of the review discussions with any clearer understanding of what their managers wanted them to accomplish. Their potential was not being developed to either their or the company's advantage.

Generic form. Reviews were conducted using a typical review form that limited discussion to such criteria as "achieves maximum production" and "keeps self busy" under the headings of "efficiency," "dependability," "initiative," and "attitude." The form was the same for everyone. There was no differentiation among departments, positions, and experience levels, and no way to track an employee's progress beyond the most basic levels. Often, half the items on the form were checked off as "not applicable." With such vague criteria and a limited range of responses, it was easy for a busy manager to conduct a review without giving much, if any, thought to the employee's progress.

Great expectations. Another problem we found was that employees were being reviewed and evaluated without first being told what was expected of them. Managers were waiting until the formal review to tell employees what they should have been doing. This meant that the time set aside for review discussions was being used to resolve problems caused by poor communication, problems that should have been resolved long before.

Further impetus for change came from management-training classes, where review-session roleplaying revealed that the form inhibited two-way discussion. The managers believed they had to base their comments on the content of the form and complained that sticking to its questions and responses limited their ability to 
have genuine conversations with their employees. The discussions were closed instead of open-ended, and didn't allow for any flexibility.

To address those problems, we began experimenting with review forms customized for each position in each department. That effort became very frustrating, as the degree of detail required proved insurmountable. Adding even more layers to account for developmental differences between employees was clearly out of the question. At the other extreme, simply giving managers a blank piece of paper would not provide enough direction. A format was needed that would be flexible enough to be customized for each department yet provide a framework for planning and evaluating an employee's progress. The solution, as it turned out, was in changing not just the form but the entire concept of reviews.

\section{Form Follows Function}

We wanted our managers to begin viewing employee development as a way to improve their department's performance and to take even more ownership for the success $\longrightarrow$ or failure - of their employees. Harvey's high-level management courses had been designed around Paul Hersey and Ken Blanchard's situationalleadership theory. That theory is based on the concept that a manager's leadership stylewhether providing coaching, training, or feedback-should be tailored to the development level of each employee. ${ }^{1}$ For example, a brand-new employee may require a great deal of instruction from the manager, while the more-experienced employee probably works best in a consultative relationship.

${ }^{1}$ Paul H. Hersey and Kenneth H. Blanchard, Management of Organizational Behavior:

Utilizing Human Resources, 5th Edition (Englewood Cliffs, N.J.: Prentice-Hall, Inc., 1988).
Hersey and Blanchard contend that the most effective leaders will recognize the stages their employees are in and respond with the appropriate types of direction and support.

When we began to look at the situational-leadership concept, we realized that an individual's development is really a continual cycle of setting goals, providing the corresponding training and feedback, accomplishing the goals, and setting new, higher goals. Our reviews, on the other hand, were based on criteria that did not change as employees grew in their jobs. Review after review, an employee's performance was evaluated against the same measures. Since we wanted our managers to develop their employees, we had to devise a process that would guide the managers to provide the employees with the appropriate type of direction.

Jo/Joe Perfect. Tossing out the standard review form, we came up with a new form-called the Personal Development Plan (PDP)—that stresses developing performance. The new form (Exhibit 1) has managers begin by tailoring a unique set of performance goals for each person they supervise. The "Development Outline" section of the form has each manager commit to a training plan for developing the employee, and specifies how the manager will help the employee to achieve the performance goals. The last section provides space to record the manager's and employee's feedback from their follow-up discussion-a meeting where they talk about how the employee performed against his or her goals.

The PDP has the manager and employee prepare goals based on technical skills (those required to perform the routine tasks associated with the position), interpersonal skills (how the employee interacts with staff members and guests on either a written or oral basis), and supervisory or selfmanagement skills (how well the employee organizes his or her time, acts responsibly, or leads others).

We knew we needed to identify the skills involved with each position. Rather than try to define those specific skills ourselves, however, or fall into the "one size fits all" trap, we asked those who knew best-the managers-for help. And instead of having them define minimum standards of performance, we asked for perfection.

"It is difficult to expect top performance from employees if you only define the least you expect from them," Kline explained. Instead of asking for basic job descriptions, we asked our managers to visualize a fully developed employee for each position and to think about how that ideal employee would perform. We then asked for a written description of that performance. At Harvey Hotels, that perfect employee is a paradigm referred to as "Jo/Joe Perfect."

Next, we took those descriptions and transformed them into standards that the managers could use in setting initial goals. But we didn't make those standards basic job descriptions. We wanted managers to customize individual performance goals for each employee they supervise - to set goals that employees could work toward instead of merely to rise above.

This level of flexibility put a lot of responsibility in our managers' hands, and experienced managers jumped at the opportunity. To assist new managers, we provided a list of suggested goals as a way to help them conceptualize and define their own expectations. No matter how the goals are set, the purpose is to give an employee a clear idea of the performance his or her manager expects and will reward. 


\section{EXHIBIT 1}

The Personal Dovelopment Plan form

\section{HARVEY HOTEL COMPANY \\ PERSONAL DEVELOPMENT PLAN AND EVALUATION

This is the development plan that will be used as a guide during orientation, training and the review process. Listed below are three categories. Under each category the manager should identify the skills that are required to meet the standard performance level for this position. The employee is responsible for learning and performing these skills to the manager's standard level. The manager is responsible for communicating these job requirements and ensuring they are taught. This list may need to be updated between formal review dates, if the employee takes on additional responsibilities.

\section{MAJOR TECHNICAL SKILLS}

$\begin{array}{cc}\text { Meets } & \text { Needs } \\ \text { Standards } & \text { Improvement }\end{array}$

1.

2.

3.

4.

5 .

Development Outtine: Discuss how and when training will be accomplished.

Review Comments: Discuss, if necessary, how consistency, efficiency or accuracy of any of these goals can be improved. Also note, if applicable, areas of exceptional performance that have exceeded expectations.

Appraisee's and Additional Manager's Comments: (Based on review discussion.)

COMMUNICATION/NTERPERSONAL SKILLS (Including teamwork)

\section{Meets}

Standards

1.

2.

3.

4.

5.

Development Outline: Discuss how and when training will be accomplished.

.
Needs Imorovement

Development Outine: Discuss how and when training will be accomplished.

Review Comments: Discuss, if necessary, how consistency, efficiency or accuracy of any of these goals can be improved. Also note, if applicable, areas of exceptional performance that have exceeded expectations. 


\section{A Plan for Interaction}

While setting goals is critical, the process involves far more interaction than simply telling the employees what characteristics they must possess to be ideal employees. The manager also is expected to show how to achieve those goals. The manager walks through each goal with the employee, talks about the specific things to be learned or accomplished, and indicates how the manager will help the employee accomplish the goal. Sometimes this means the manager plans time for the employee to review training manuals or to shadow a supervisor. In other instances, the manager may plan weekly one-on-one meetings with the person.

Often the manager finds that accomplishing a goal is up to the employee. For example, a waiter may have the goal of reporting to work ten minutes prior to his shift, and that's his responsibility; we can't train him on how to get to work on time. But by using the PDP, the manager has made it very clear what is expected of this waiter. We often forget that if people just know what to do, they'll do it. The PDP gives us an opportunity to make the important issues perfectly clear.

Prior to review time, the manager and employee pull out their personal copies of the PDP and prepare their own evaluation of the employee's performance. They then meet and discuss how the employee performed against the goals previously set. Ultimately, they must agree upon whether each goal was met. The results of the discussion are recorded on the original PDP.

At that point, the review is only half complete. Any aspect of the employee's performance that was not up to expectations is carried forward onto a new PDP form as an ongoing goal. The manager and employee discuss how training should proceed to reach that goal and the plan is recorded in the development-outline section of the PDP. Then, the manager and employee together set entirely new goals to build on those that have been met and the process begins anew (see Exhibit 2). The intent is to coordinate the employee's desired developmental direction with the organization's needs. It gives the manager an opportunity to ensure that they both are working according to the same agenda.

Different strokes. The primary focus of the new review process is on growth rather than failure. The PDP format doesn't make references to "strengths" or "weaknesses." A goal not met is simply reevaluated. It may have been that the training was inadequate to meet the goal or that the employee needs better direction in figuring out how to accomplish it. The process is more positive than previous approaches in that employees are encouraged to move forward rather than look back. And it's more productive in that the employees now have personal goals that they see will contribute to the department's success.

Another significant change is a movement away from the idea of doing reviews only once a year. Once our managers learned how to set effective goals, they didn't want to wait a year to review performance. In fact, most decided to meet with their employees on a quarterly basis. Many managers also began to use the PDP for informal discussions, just to see how things were going. It became clear that, if nothing else, the revised process was building mentoring relationships between managers and their staff.

The process of setting goals together-and creating something brand new-forced managers and their employees to be open with one another. The managers had to ask the employees what their own goals were, and after setting new ones, it became very logical for a manager comfortably to say, "Let's talk about how you're doing with your goals and see what you need to focus on." This type of open dialogue supports the company's philosophy of being honest and direct. The managers and their employees also discovered that they liked the new style of communicating.

When we rolled out the PDP, many managers expressed concern about the freedom this gave the employee to control the review discussion. After using the new process, however, our managers found that most of their employees were harder on themselves than the managers would have been. Ninety-nine percent of the time, when employees were asked how they felt about reaching a particular goal, they gave an honest answer and were in agreement with their manager. The manager and employee could then discuss frankly the 1 percent they disagreed over.

\section{Opening Lines of Communication}

Tim Milstead, chief engineer at Bristol Suites, Dallas, remarked that the PDP forced him to clarify his definition of success for his maintenance engineers. "Previously, I knew in my mind what a great engineer would be able to accomplish, but I wasn't telling this to my engineers! At review time, we would talk about their performance but I wasn't clear about what exactly they needed to do to meet my expectations or how they should go about their jobs. When I was asked to help design a list of suggested PDP goals, I stopped for the first time and wrote down my standards. Now I can share these with my engineers and, at the same time, make them their standards." 


\section{EXHIBIT 2}

\section{An example of the performance-review cycle}

Step 1: The F8I manager lists the technical goals require of a now banquet walter as soon as the waiter is hired. (Intorporsonel and managerial stuls ana also listail at this time. Por tha sake of this illustration, only technieal skills ane shown.)

Step 2: Shortly after the hire date, the manager outlines how the waiter will be trained to achieve the goals outlined in Step 1.

Step 3A: About 90 days after the hire date, the manager evaluates the waiter's performance against the goals from Step 1 as either "Meets Standards" or "Noeds Improvement." Written feedback is recorded in the section "Review Comments."

Step 3B: At the same time, the employee records his or her comments on the form, some of which will be the result of the review meeting with the manager.

Step 4: During the second half of the review, a new PDP is prepared. Goals marked as tNoeds Improvement" are cetied lonvard, new objectives that bulld on goals already achieved are edice, and a new development outline is prepared for each goal (ust as in Step 2).

The cycle (Steps 1-4)

is repeated for each

performance-review period.

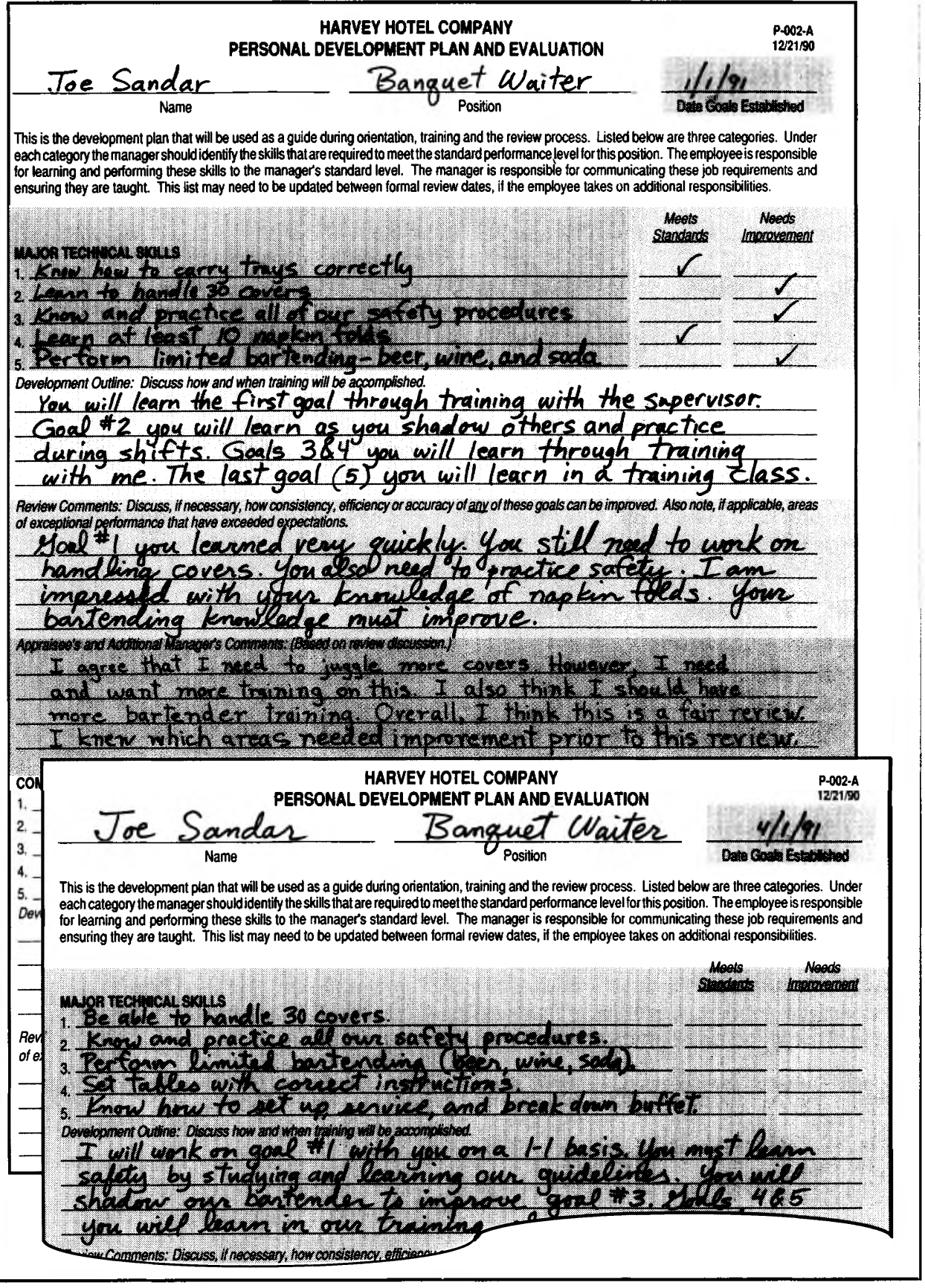

Milstead uses the following example as praise for the PDP. One of the engineers he supervised felt he was ready to become a supervisor. "I didn't think he was ready to take on this responsibility, and we were at a point of disagreement. When the PDP was introduced, I saw an opportunity to use it to our advantage. I prepared a list of skills required to be a maintenance supervisor and we sat down together and reviewed it. I said, 'Let's take a few of these skills and make mastering them your immediate goals.' We took it a few goals at a time and it wasn't long before he actually was ready for more responsibility. What I liked about what we did was that we set him up to succeed. He earned his promotion."

Aligning objectives. Bob Romero, Harvey's director of information systems, found that the PDP process was the way for him to align his managers' goals to his department's goals. "I establish my department's goals for the trimester, allocate them to my managers, and help them design a critical path for the goals' accomplishment. Because we have this 'laundry list' of things to do, I can sit down with them anytime, talk about their progress, and make any needed adjustments before the end of the period. At the start of the next trimester, I look at the department's new goals and, with each of my managers, prepare with 


\section{SITUATIONAL LEADERSHIP}

Situational Leadership, a theory developed by Paul Hersey and Ken Blanchard, is based on the premise that no one style of leadership is best. That is, different styles should be used depending on the person and situation. Managers should evaluate the development of each of their employees and tailor their style to match the type and degree of supervision each person requires. ${ }^{1}$

A person evolves through four development stages-D1 through D4according to Hersey and Blanchard. A person in the D1 stage is the brand-new employee who needs to learn and understand his or her job responsibilities. As employees progress to the D2 stage, they have learned the basics and now begin to focus on mastering their jobs. A great amount of skills-learning occurs at this stage. Employees in the D3 stage know exactly what is expected of them and have mastered their basic job skills. They are now ready to concentrate on refining their techniques and possibly assuming additional responsibilities. When a person reaches the D4 stage, he or she is an expert at their job and knows exactly what his or her responsibilities are. ${ }^{2}$

The situational-leadership theory contends that effective leaders will tailor their leadership style to an employee's stage of development. Hersey and Blanchard propose four stages of corresponding styles. A person in the D1 stage requires a great deal of direction from their manager and needs to know the what, where, when, and how of their job. The appropriate leadership style is to "tell"; that is, to provide detailed information and to supervise closely the employee's progress. As persons move into the D2 stage, they need both instruction and guidance, as they are ready to learn how their job fits into the organization's mission. The ideal leadership response is to provide direction but also to encourage communication by asking for suggestions and explaining decisions. The manager needs to "sell" the job and make sure the employee understand the "whys" behind the "hows" so that he or she will understand the job's significance. People in the D3 stage work best when their manager adopts a consultative role, provides support, and shares the decision making. The employee understands what needs to be done and how to do it; what he or she needs is advice and encouragement. A person in the D4 stage works best with minimal direction. They obtain their own gratification from their jobs and work best when the manager leaves them "to run their own show."

Hersey and Blanchard further contend that we use three different types of skills when we work: technical, human (interpersonal), and conceptual (managerial). Each person is at a different level of development with respect to their abilities to use those skills. ${ }^{4}$ For example, a person may understand how to perform a job task but be unable to organize and prioritize his or her day. Thus, that individual may be a D3 with respect to technical skills and a D1 in management abilities. The supervisor needs to understand the level the employee is at in each of those areas and provide the appropriate style of leadership.-K.W.

'Paul H. Hersey and Kenneth H. Blanchard, Management of Organizational Behavior: Utilizing Human Resources, 5th Edition (Englewood Cliffs, N.J.: Prentice-Hall, Inc., 1988), p. 170.

${ }^{2}$ Kenneth H. Blanchard, Patricia Zigarmi, and Drea Zigarmi, Leadership and the One Minute Manager (New York, N.Y.: William Morrow and Company, Inc., 1985), p. 69.

${ }^{3}$ op. cit., p. 30 .

${ }^{4}$ Hersey and Blanchard, p. 7.

them new PDPs and update their own goals. We are absolutely able to accomplish a great deal more because of this process.

"Previously, I knew what I wanted my department to do and I orally tried to allocate responsibilities as we went along. Because my managers were receiving reviews yearly, they had nothing to look at for a specific block of time and say, 'this is what he expects me to accomplish." "

Romero has a unique challenge because his managers are all out in the field. "I can't be with them all the time," he commented, "but they always have their PDP to refer to. They've told me it gives them a lot of direction and guidance when they have questions or become confused. It's the glue that holds the department together. The best part about it is that it really crystallizes our objectives. It forces my managers into goal achievement. There is no gray area anymore and no one can hide behind any excuses, including me."

Train the trainer. Kymberly Nielson, assistant manager of
McArthur's Restaurant at the Harvey Hotel, Addison, found the PDP helpful when she promoted an employee into a new position. "I had a waiter who was excellent. He knew the menu and set the standards for the other waiters; he really owned that job. So, I decided he should do the training and take on additional management responsibilities," Nielson reports. "I gave him a new title and more moneybut I forgot to give him the skills to go with them. I had taken him from a position where he knew everything and put him in a position where he knew almost nothing."

The introduction of the PDP concept had an immediate impact on Nielson. "It was as if a light bulb had gone on when I realized that having great technical skills doesn't mean you're ready to supervise." Nielson addressed the situation by establishing managerial and interpersonal goals with the waiter and designing a training program to develop the skills he needed in his new position. "I feel now as if I'm building something here. Actually, we both are, together."

Even in instances when things don't work out for an employee, the PDP is proving to be valuable in communicating standards. Hotel controller Scott Anderson used it to set goals for a cashier who was having trouble learning the fundamentals of the job and to address how he would help her. "She still didn't make it," he said. "She knew she was in over her head in that position. But she said in her exit interview that she definitely knew exactly what was expected of her and she had not achieved her goals."

\section{New Challenges}

The PDP review is clearly more challenging for management. The up-front tasks of goal-setting and formal planning are very timeconsuming and require hard 


\section{HARVEY HOTEL COMPANY- A PERFORMANCE-BASED ORGANIZATION}

concentration. "You have to find time to work on it when you're clear, fresh, and able to be creative," said one director of sales. Making time for reviews is a major issue for a director of housekeeping, for example, who must review 50 or more employees. Many managers also found that the review discussions were taking twice as long, often requiring more than one meeting to complete.

Other managers mentioned the challenge of finding new goals for employees who already thoroughly knew their jobs. "I had a banquet waiter who had developed into a 'D4,'" commented a banquet manager, referring to the situationalleadership term for a fully developed employee. "He was my best waiter, but every time I brought up the idea of becoming a manager, he turned me down. In my mind, it was the only way I could think of for him to grow. At his review, which took about ten minutes to complete, I didn't know what else to say beyond 'keep it up.' I wasn't asking for more and, as a result, he wasn't offering more."

According to that manager, the PDP turned the situation around. "When I was forced to set goals with this waiter, I didn't know what to do. As a last resort, I asked him to help me come up with ways to do things better. It turned out he had a lot of great ideas and we were able to make a pretty hefty list. Even though my waiter is terrific —or maybe because he isI'm expecting a lot more from him now and he's really taken to the challenge. It's created excitement throughout the department."

The process requires a much greater commitment from the manager. It takes a great deal more time and thought to sit down with each employee to set specific, measurable goals and define a plan of action to reach them. It demands communication to a degree that

Harvey Hotel Company is a partnership of five professionals in the hotel and realestate industry, three of whom are graduates of the Cornell University School of Hotel Administration. When forming this company, the partners wanted to create an environment different from any organization of which they had previously been a part. What they came up with was an organizational philosophy of exceeding guest expectations.

"Exceeding expectations" means that every employee has complete authority to do whatever it takes to make a guest happy. The partners realized that, by giving employees this responsibility, the organization could not tolerate a formal chain of command, "not my job" excuses, or structured policies and procedures. There's no tolerance of big egos or individuals sensitive to criticism. Everyone owns responsibility for the company's success and is encouraged to offer suggestions and ideas for improvement. The company's collateral material for new clients states: "Our bellmen make executive decisions. Our managers carry bags."

Rather than burden managers with rules and instructions, the partners elected to hire smart people who can take charge, make decisions, and make things happen. The only set of guiding instructions are the Ten Commandments and the Golden Rule. This philosophy fosters an atmosphere of honesty and openness.

Attracting smart people is one thing, and keeping them challenged is another. The partners realized they needed to create a performance-based environment where those leaders who could make a significant impact were rewarded with more responsibilities. The company has more than one success story of a strong performer who became general manager within four years. Those who respond to the authority they are given thrive and those who are fearful of it-well, they move on to another hotel company.

At Harvey Hotels, there is no such thing as standard raises or compensation for time. Growth and success with the company depend solely on performance.- $K . W$.

perhaps wasn't there before. Nevertheless, most Harvey Hotel managers immediately embraced the new program. In many ways, we were simply formalizing what our strongest managers were already doing. Many of them, who were very good at planning and organizing training, had earlier abandoned the old review form because it was too restrictive. Instead, they were writing their own reviews free-form.

Many managers were thrilled with the freedom the PDP gave them. But others were nervous about the amount of trust that was put in their leadership ability. Newer managers were uncomfortable with being held responsible for defining their standards of excellence. It also became obvious that managers who were still learning how to organize their departments were not finding the time to complete the PDPs or, more important, buying into the concept. We reminded ourselves that this situation existed when we were using the old review form, too. The
PDP process simply brought it to light, and gave us a chance to provide those managers with more training and direction.

We also found that our managers became better trainers. One of the best aspects of introducing the PDP concept was that managers began to prepare customized training programs based on each individual's set of goals. They took training into their own hands and tailored it based on their needs, a method much more effective than sitting everyone down with the same training manual or with any canned program.

There is the risk that an overenthusiastic manager might inadvertently overload his or her employees with goals. That risk is reduced, however, as managers become more familiar with the process. We also have the managers' supervisors review the PDPs in order to catch anything that is out of whack. We told our managers, if you make a mistake with a goal, just fix it; revise the PDP and move on. 
While most employees also were excited about the new PDP program, others were more nervous than before. This is because they realized that, in order to stay with the company and earn more responsibility and money, they would have to meet specific, measurable goals. They also found that as soon as they met one goal they would be presented with another. That can be very intimidating.

We noticed a positive change in attitude among our employees as well. They used to dread reviews, especially if the manager did all of the talking. Now, we're finding that reviews are less worrisome to employees because there are no surprises or unknowns. Through the initial process of setting goals, employees have their objectives clearly outlined and know exactly what's expected of them. Chances are they've already met with their managers informally to discuss their performance and the review is just one more in a series of conversations. This new format turns the review into a two-sided discussion-something we wanted but were unable to accomplish with the old form.

Hiring Jo/Joe. The new review process produced an excellent, albeit unanticipated, side benefit. Managers are having greater success in the hiring process because they are constantly thinking about their own standards. When they interview, they are able to measure the candidates' skills against the structured criteria that they personally established-Jo/Joe Perfect-and use on the PDPs. The process gives everyone a fair opportunity to be successful.

By the same token, managers can also identify the hiring mistakes more quickly-the people who just don't have the capabilities for a certain position or who are unwilling to give their all or be held accountable. Clearing the dead wood has helped improve morale, too: the remaining employees have taken off and are really performing.

\section{Getting It Right}

Since its introduction, the form has been modified to allow the users to write more. The content hasn't changed, however. And if we were to do it all over again, we wouldn't alter the process or the way we designed the form. We spent a great deal of time getting input from managers about what they liked and did not like about review forms, mocking up samples, then tearing them apart. We probably went through a dozen versions because we kept getting suggestions for improvement from different managers. We also tested the process with different levels of managers and staff.

Where we didn't spend enough time, however, was in the rollout. We first presented the PDP to our GMs. With their support, we and the hotels' personnel managers held training classes with other department managers. In retrospect, it wasn't enough. We should have worked much more closely with the managers as they prepared their first PDP.

The problem, if you can call it that, was that many of them were so excited, they decided to go ahead and start working up PDPs, even though we told them they could ease into it by waiting until their employees were due for reviews. While having a list of suggested goals helped a great deal, initially there was a lot of confusion on how to set them and we failed to respond with more direction. Fortunately, even though some managers became confused and frustrated, their enthusiasm didn't wane. They liked the concept enough to give it a chance.

\section{The Measure of Success}

While the new PDP process is only about a year old, we count it a success based on a number of criteria, including an audit of completed PDPs, performance statistics, and feedback from our employees. The results indicate that managers indeed have been able to improve the performance of their departments and that employees, especially the brightest individuals, enjoy having challenging new goals to work on instead of just falling into a daily routine. They can readily see the payoff and now feel they have a great deal more control over their own success.

The new performance-review program better suits the Harvey Hotels style as well. "We don't have a lot of rules, bureaucracy, approval levels, or even a formal chain of command," commented Kline. "The PDP matches up well with Harvey Hotel's long-standing philosophy of giving employees authority to make decisions on their own and be very responsive to guests' needs. You need smart, competent people to make this approach work, however. With the PDP, we have found a way to identify, develop, and reward such people in our organization. The talent and potential were there all along. We just weren't tapping into it in the best way we could. Now, the company is building on its strengths and getting a very nice return on its investment.

"Introducing the PDP has helped create an environment where our company's mission to exceed guest expectations has a direct relationship to an individual's success with the Harvey organization," Kline continued. "Our service has always been good; now, we have a way to make it consistently outstanding." 